constitute another possibility of geotropic orientation. Surely it seems that, while otolith and otocyst are probably devices for strengthening and rendering more definite the geotropic response, yet it may turn out in the end that protoplasm itself possesses geotropic irritability.

\title{
An Experiment to test recent Theories as to Movements of Nerve Cells.
}

By Henky H. Godidard,

Clark Cniversity, Worcester, Mass.

The following experiments of $\mathrm{Mr}$. Goddard were reported by Dr. Hodge :

Considerable attention has been directed in recent years toward attempting to explain various functional states of the nervous system, hysterias, sleeping and waking, even psychic conditions, association of ideas, memory and forgetting, by amoeboid movements of nerve elements. For the most part, when announced, these theories have had about as much foundation in experimental evidence as similar ancient theories as to flow of "spiritus animalis" or ideas of making and breaking of electric contacts between nerve fibers and nerve cells, before the fibers were discovered to be outgrowths of the cells.

In line with Ramón y Cajal's theory, that the dendrites represent receiving poles, attention has tended to focus on these processes, especially on their terminal twigs and more especially still on their gemmular expansions, the "contact granules." Berkley, in 1895, in chronic alcohol poisoning, and in 1896 , with a number of other pathological conditions, pointed out the fact that the terminal twigs of the dendrites, as well as their proximal portions in some cases, presented, instead of their usual appearance, a beaded, moniliform, varicose condition, with very few contact granules or none at all. $\mathrm{He}$ naturally attributed these appearances to the pathological causes in question, although, before doing so, it would have been safer logic to have studied first the possible changes dependent upon phases of normal function. About the same time Demoor (La 
Plasticite Morphologique des Neurones Cerebraux, I896), obtained precisely similar findings in animals poisoned with morphine, chloral hydrate, chloroform and also in those whose cerebral cortex had been stimulated electrically (for only five minutes). He also investigated, in no very adequate manner, normal conditions of rest and fatigue, but with wholly negative result.

The following experiment was devised to obtain preparations of nerve cells quickly enough, if possible, to catch them in their sleeping and waking states. It consisted simply in cutting through the entire head of the animal at a single blow with a very sharp thin knife, the parts of the head falling instantly into large culture dishes of Cox's solution, warmed to $39^{\circ} \mathrm{C}$. In the two experiments to be described puppies, about seven weeks old, were used, sisters from the same litter. It was hoped by using the surfaces coming first in contact with the killing fluid, to obtain the cells before they could extend or retract, in case their processes actually changed position.

In the first experiment one puppy was killed at 4 o'clock P. M., awake, though rather sleepy, after having played about actively the greater part of the day. The sister puppy was kept awake from this time until 7 P. M. of the same day, when she was allowed to go to sleep. Thinking that sleep might reach its maximum depth in about $1 \mathrm{x} / 2$ hours, it was intended to cut the brain at $8: 30$. However, after sleeping soundly until 8:05 she suddenly opened her eyes, yawned, stretched and got up, evidently pretty well awake. By very gently laying her in position again, however, she was asleep by about 8:10 and the cut was made, after being asleep again for only 5 minutes, at 8:15. Results of the experiment may be seen in the following table, as related to the pyramidal cells of the cer. ebral cortex.

Cells with dendrites not varicose,

Cells with dendrites slightly varicose,

Cells with considerable varicosity of dendrites,

Cells with much varicosity,

Whole number studied,

Cells showing varicosity,

Cells with much varicosity,

$\begin{array}{cc}\text { Puppy awake, } & \text { Puppy asleep, } \\ 4 \text { P. M. } & \text { 8: I 5. M. } \\ 21 \text { I } & 107 \\ 36 & 3 \\ 12 & 6 \\ 49 & \text { I } \\ 308 & 117 \\ 31.1 \% & 8.5 \% \\ 15.9 \% & 0.8 \%\end{array}$


The appearance of the specimens was even more striking than might seem to be indicated by the table, but, as far as the mere state of waking and sleeping is concerned, the result is the reverse of that called for by current theories. In the sleeping animal, where contacts should be interrupted, the contact granules being retracted into the moniliform swellings, the dendrites are, almost all of them, beautifully expanded. In the waking animal, where perfect contact of the cells is called for, a large percentage are retracted and varicose. The result, if it can be taken to indicate anything, ciearly tends to confirm Demoor's experiments, extending his results, moreover, into the sphere of normal functional activity of the cells. According to this view the varicosity of the dendrites corresponds to a fatigued or abnormal condition, whether awake or asleep. The waking puppy, in our experiment, was partially fatigued; the sleeping puppy, partially rested, the $\mathrm{I}$ hour and Io minutes sleep having sufficed, however, to bring the cells into a pretty completely rested condition in this respect.

The second experiment was made with the purpose of definitely testing this point. The first of two sisters was taken on waking in the morning, at 7 o'clock. The second was kept awake, playing and running about the entire day, until 5:40 P. M., when it became practically impossible to keep her awake without doing violence to normal conditions. After five minutes sleep, the cut was made at 5:45 P. M.

It is difficult to find a single varicosity on the dendrites of the morning puppy. For long distances in the cortex of the evening puppy it is difficult to find a cell whose processes are not more or less varicose. The results are certainly as striking as those obtained by either Demoor or Berkley for pathological conditions. The experiments are being continued by $\mathrm{Mr}$. Goddard, but confirming and extending Demoor's work, as they do, it was thought advisable to make the above brief report.

Specimens showing the above points were demonstrated. 